American Journal of Applied Sciences 8 (4): 348-354, 2011

ISSN 1546-9239

(C) 2010 Science Publications

\title{
Experimental Investigation on Performance and Emission Characteristics of Low Heat Rejection Diesel Engine with Ethanol as Fuel
}

\author{
${ }^{1} \mathrm{P}$. Lawrence, ${ }^{2} \mathrm{P}$. Koshy Mathews and ${ }^{3} \mathrm{~B}$. Deepanraj \\ ${ }^{1}$ Department of Mechanical Engineering, Research Scholar, Anna University, Coimbatore, \\ Priyadarshini Engineering College, Vaniyambadi-635751, Tamilnadu, India \\ ${ }^{2}$ Department of Mechanical Engineering, Kalaivani College of Technology, \\ Coimbatore, 641105, Tamilnadu, India \\ ${ }^{3}$ Department of Mechanical Engineering, Adhiparasakthi Engineering College, \\ Melmaruvathur, 603319, Tamilnadu, India
}

\begin{abstract}
Problem statement: Depleting petroleum reserves on the earth and increasing concerns about the environment leads to the question for fuels which are eco-friendly safer for human beings. The objective of present work was to investigate the effect of coating on piston, cylinder head and valves of a Diesel engine on the performance and emission characteristics of exhaust gases using wet ethanol (5\% water) as a fuel. Approach: In this study the effect of Zirconia coating on the performance and emission characteristics of diesel engine was investigated using ethanol as sole fuel. For this purpose the cylinder head, valve and piston of the test engine were coated with a partially stabilized Zirconia of $0.5 \mathrm{~mm}$ thick by the plasma spray coating method. . For comparing the performance of the engine with coated components with the base engine, readings were taken before and after coating. To make the diesel engine to work with ethanol a modification was done. Results: The engine's performance was studied for both wet ethanol and diesel with and without Zirconia coating. Also the emissions values are recorded to study the engine's behavior on emissions. Satisfactory performance was obtained with Zirconia coating compared with a standard diesel engine. The brake thermal efficiency was increased up to $1.64 \%$ for ethanol with coating and there was a significant reduction in the specific fuel consumption. The NOx, CO and $\mathrm{HC}$ emissions in the engine exhaust decreases with coating. Conclusion: Using ethanol as sole fuel for a LHR diesel engine causes an improvement in the performance characteristics and significant reduction in exhaust emissions.
\end{abstract}

Key words: Partially Stabilized Zirconia (PSZ), Low Heat Rejection (LHR), heat rejection, Exhaust emissions, emission characteristics

\section{INTRODUCTION}

The rapid depletion of petroleum fuels and their ever increasing costs have lead to an intensive search for alternate fuels. The most promising substitutes for petroleum fuels are alcohols- mainly ethanol and methanol. It has been predicted that by the year 2030 all the present sources of fossil fuels would get depleted and the world would come to a stand still for need of fuel power. So, it is high time that scientists and technologists developed an alternate fuel that would run on the existing engines without many modifications and also one that would cater to the ever increasing power needs of the countries and domestic market (Beele et al., 1999).

Although replacing diesel fuel entirely by alcohols is very difficult, an increased interest has emerged for the use of alcohols and particularly lower alcohols (methanol and ethanol) with different amounts and different techniques in diesel engines as a dual fuel operation during recent years. Ethanol is one of the possible fuels for diesel replacement in Compression Ignition (CI) engines. It can be made from raw materials such as sugarcane, sorghum, corn barley and cassava, sugar beets using already improved and demonstrated technologies. Besides being a bio massbased renewable fuel, ethanol has clean burning characteristics and high octane rating. The application of ethanol as a supplementary compression-ignition fuel may reduce environmental pollution, strengthen agricultural economy, create job opportunities, reduce diesel fuel requirements and thus contribute in conserving a major commercial energy source. There is need to develop alternate fuels to cater to the needs of the

Corresponding Author: P. Lawrence, Department of Mechanical Engineering, Priyadarshini Engineering College, Vaniyambadi-635751, Tamilnadu, India Tel. +91 9444273966 
thirsty industries (Hansen et al., 2005; Ciniviz, 2010). Existing research results shows that ethanol is the best alternate fuel. Self-Ignition temperature for ethanol and 'aquanol' (70\% ethanol and 30\% water) is greater than that of petrol. So, we need a high intensity spark plug for better performance.

There are several techniques involving alcoholdiesel dual fuel operation. The high self-ignition diesel fuel ensures the ignition of alcohol in dual fuel operation. The most common methods for achieving dual fuel operation are:

- Alcohol fumigation-The addition of alcohols to the intake air charge, displacing up to $50 \%$ of diesel fuel demand

- Dual injection -Separate injection systems for each fuel, displacing up to $90 \%$ of diesel fuel demand.

- Alcohol-diesel fuel blend -Mixture of the fuels just prior to injection, displacing up to $75 \%$ of diesel fuel demand

- Alcohol-diesel fuel emulsion -Using an emulsifier to mix the fuels to prevent separation, displacing up to $25 \%$ diesel fuel demand

The easiest method by which alcohols can be used in diesel engines is in the form of blends. For lower alcohols, this approach is limited to ethanol because methanol is not soluble. Methanol has very limited solubility in the diesel fuel. Since low power stationary diesel engines are commonly used in the agricultural and transport sectors, which is essential to study their performances using ethanol-diesel blends.

The thermal efficiency of the diesel engines can be increased by reducing the heat loss to the surroundings by means of coolant and exhaust gases. The heat can be transfer from the combustion chamber to the piston, to the combustion chamber walls and finally to the cooling water circulated in the cooling water jacket around the cylinder. The heat transfer can be minimized by reducing the heat that is transferred from combustion chamber to the pistons. This leads to the idea of insulating the piston and cylinder walls. These types of engines are known as Low Heat Rejection (LHR) engines. This can be realized by coating the pistons, cylinder walls with ceramics which can withstand high thermal stresses (Srinivasan and Saravanan, 2010; Modi and Gosai, 2010; Al-Hasan, 2007; Jaichandar et al., 2003). They have low thermal conductivity thus reducing the heat flux into the piston and thus reduction of heat transfer to the coolant is reduced. When cylinder cooling losses are reduced, more of the heat is delivered to the exhaust system. Thus, efficient recovery of energy of the exhaust improves the thermal efficiency of a low heat rejection engine. However, installing in the engine configuration even without heat recovery systems, some of the heat is converted to piston work and increases thermal efficiency. Therefore, LHR engines without exhaust heat recovery systems are worth studying (Kaleemuddin and Rao, 2009; Bekal and Babu, 2008; Garcia et al., 2008; Al Hasan, 2003).

The peak burned gas temperature in the cylinder of an internal combustion engine is $1200 \mathrm{~K}$. Maximum metal temperatures for the inside of combustion chamber space are limited to much lower values by a number of considerations and the cooling for the cylinder head, cylinder and piston must therefore be provided. These conditions lead to heat fluxes to the chamber during the combustion period. The flux varies substantially with the location. The regions of combustion chamber that are contacted by rapidly moving high temperature burned gases generally experience highest fluxes. In regions of high heat flux, thermal stresses must be kept below levels that would cause fatigue failures. Heat transfer affects engine performance, efficiency and emissions. For a given mass of fuel within the cylinder, higher heat transfer to the combustion chamber walls will lower the average combustion gas temperature are pressure and reduce the work per cycle transferred to the piston. Thus the power and efficiency are affected by the magnitude of engine heat transfer. The exhaust temperature also governs the power that can be obtained from the exhaust energy recovery devices such as turbochargers. The fan and water pump power requirements are determined by the magnitude to the heat rejected. Lesser heat transfer require less cooling power requirements and hence smaller its size.

During the intake process, the incoming charge is usually cooler than the walls. During compression, the charge temperature rises above the wall temperature. Heat transfer is now from the cylinder gases to the chamber walls. During combustion, the gas temperature increase substantially and this is the period when the heat transfer rates are highest. During expansion, the gas temperature decrease and hence the heat transfer rates also decrease. Substantial heat transfer from the exhausting gases to the valves and ports occurs during the exhaust process.

\section{MATERIALS AND METHODS}

Two major obstacles of the LHR engine are component strength and tribology at high temperatures, where conventional metals and lubricants fail to perform at elevated temperatures, advanced ceramic materials provide an alternative. These materials have provided the major impetus to LHR research and development in recent decades. Principle substances of interest include nitrides and carbides of silicon $\left(\mathrm{Si}_{2} \mathrm{~N}_{4}\right.$ 
and $\mathrm{SiC}$ ); oxides of chromium, aluminum and iron $\left(\mathrm{Cr}_{2} \mathrm{O}_{3}, \mathrm{Al}_{2} \mathrm{O}_{3}\right.$ and $\left.\mathrm{FeO}_{2}\right)$; and partially stabilized oxide of zirconium, $\left(\mathrm{ZrO}_{2}\right.$, or PSZ). Low ductility, low tensile strength and low bending strength have impeded the direct replacement of metals with ceramics in conventional engine designs. Conventional piston and cylinder stresses make the application of ceramics extremely challenging. Large piston ring loading forces produce large stresses and large friction forces. To reduce these forces, modifications to piston and connecting rod mechanics would decrease the demands which are currently placed upon tribological research. Both monolithic ceramic components and ceramic coatings have been used by various LHR engine researchers.

It is another kind of high temperature resistant coating which has recently been developed. The main objective of this coating is to provide thermal insulation to metallic components at elevated temperature especially for diesel, gas turbine and aeroengine applications. Improvement of thermal efficiency and reduction of the NOx level in TBC coated piston heads of diesel engine have been studied and the thermal gradient between the substrate and the surface coating observed.

Partially Stabilized Zirconia (PSZ): Partially stabilized Zirconia is a mixture of zirconia polymorphs, because insufficient cubic phase-forming oxide (Stabilizer) has been added and a cubic plus Meta stable tetragonal $\mathrm{ZrO}_{2}$ mixture is obtained. A smaller addition of stabilizer to the pure zirconia will bring its structure into a tetragonal phase at a temperature higher than $1,000^{\circ} \mathrm{C}$ and a mixture of cubic phase and monoclinic (or tetragonal)-phase at a lower temperature. Therefore, the partially stabilized zirconia is also called as Tetragonal Zirconia Polycrystalline (TZP). Usually such PSZ consists of larger than $8 \mathrm{~mol} \%$ (2.77 wt \%) of MgO, 8 mol\% (3.81 wt \%) of $\mathrm{CaO}$, or 3-4 mol\% (5.4-7.1 wt \%) of $\mathrm{Y}_{2} \mathrm{O}_{3}$. PSZ is a transformation-toughened material. Micro crack and induced stress may be two explanations for the toughening in partially stabilized zirconia.

The Micro crack explanation depends upon difference in the thermal expansion between the cubic phase particle and monoclinic (or tetragonal)-phase particles in the PSZ. Coefficient of thermal expansion for the monoclinic form is $6.5^{-6} /{ }^{\circ} \mathrm{C}$ up to $1200^{\circ} \mathrm{C}, 10.5^{-}$ ${ }^{6} /{ }^{\circ} \mathrm{C}$ for cubic form is. This difference creates micro cracks that dissipate the energy of propagating cracks (Garcia et al., 2008). The induced stress explanation depends upon the tetragonal-to-monoclinic transformation, once the application temperature over pass the transformation temperature at about $1000^{\circ} \mathrm{C}$ (Modi and Gosai, 2010; Kamo et al., 2006).
The pure zirconia particles in PSZ can metastabily retain the high-temperature tetragonal phase. The cubic matrix provides a compressive force that maintains the tetragonal phase. Stress energies from propagating cracks cause the transition from the Meta stable tetragonal to the stable monoclinic zirconia. The energy used by this transformation is sufficient to slow or stop propagation of the cracks. Partially Stabilized Zirconia has been used where extremely high temperatures are required. The low thermal conductivity ensures low heat losses and the high melting point permits stabilized zirconia refractory's to be used continuously or intermittently at temperatures of $2,200^{\circ} \mathrm{C}$ in neutral or oxidizing atmospheres. Above $1,650^{\circ} \mathrm{C}$, in contact with carbon, zirconia is converted in to zirconium carbide. Zirconia is not wetted by many metals and is therefore an excellent crucible material when slag is absent. It has been used very successfully for melting alloy steels and the noble metals. PSZ refractory's are rapidly finding application as setter plates for ferrite and titillate manufacture and as matrix elements and wing tunnel liners for the aerospace industry. PSZ is also used experimentally as heat engine components, such as cylinder liners, piston caps and valve seats.

Engine modifications: The following components are added to facilitate ethanol as a sole fuel in a diesel engine and the modified engine includes Bajaj make contact breaker, Fiat make condenser, Fiat make ignition coil, Fiat make car spark plug, 12 volt Exide battery. The modification in existing diesel engine is made in three parts as follows.

Engine cylinder head: The fuel injector is replaced by spark plug. A bush is provided for fixing the spark plug. It is placed by creating an internal thread in the bush, which is placed in the cylinder head. The bush is fitted in the cylinder using press fit for the required dimensions. As the spark plug is placed in the space provided for fuel injector, Pre-combustion chamber is created which helps fast flame propagation and smooth combustion.

High pressure port fuel injection system: In the inlet manifold the fuel injector is placed. A throttle valve is introduced for air adjustment in the inlet manifold. The fixing of fuel injector involves a circular plate which is used to connect the fuel injector and the manifold.

Ignition system: As a spark plug is introduced in the system, there is need of ignition system which requires fixing of cam profile in the shaft. The cam used is specially made for this purpose. A circular plate is introduced. This is mainly used for the fixing the condenser and contact breaker. The circular plate is clamped to the engine housing. The cam profile is 
Am. J. Applied Sci., 8 (4): 348-354, 2011

tightened by using key along with the shaft. Then the contact breaker is fixed so that it touches the cam edge at the required stage. When the cam touches the contact breaker, the current is passed to the ignition coil and hence spark is produced in the sparkplug. A 12 Volts battery is used to charge the ignition coil.

When the ignition switch is switched ON, the current from the battery passes through the ignition switch to the ignition coil. When the contact breaker switch comes in contact with the cam profile, the current is passed to the spark plug and thus spark is produced. The timing is fixed by making the fuel injection at the end of compression stroke and at the same time the contact breaker comes in contact with the cam profile. Hence a spark is produced at the end of compression stroke.

Properties of ethanol and diesel: The important properties of ethanol and diesel are listed in the Table1.

Experimental setup: The experimental work is conducted on four stroke, single cylinder, water cooled, manifold injection ethanol engine and direct injection diesel engine coupled on an eddy current dynamometer as shown in Fig. 1. The specification of the test engine is shown in Table 2.

For measuring of exhaust temperature, NOx, CO and Unburned HC level are made in the exhaust pipe. The exhaust temperature of the engine measured using digital chromel-alumel thermocouple. The NOX level is measured using NOX analyzer. The carbon monoxide and unburned hydrocarbon is measured by using infrared analyzer. Fuel consumption is measured with the help of burette and digital stop watch. The experiments are conducted at various loads from no load to full load with uncoated piston and coated piston with different fuel (wet ethanol, diesel).

Experimental procedure: Initially fuel tank and auxiliary fuel tanks are filled with right amount of required fuel. Water pump is switched $\mathrm{ON}$ to cool the stator coils of the eddy current dynamometer which gets heated up while loading. The instruments such as NOx meter and $\mathrm{CO} / \mathrm{HC}$ analyzer are connected to the exhaust pipe. Eddy current dynamometer is switched ON and set to constant torque mode. The engine is started and allowed to run for 20 minutes to attain steady state condition. Now the time taken for 25 cc normal ethanol fuel consumption is noted using stop watch. NOx, CO and $\mathrm{HC}$ emissions are noted using exhaust gas analyzer. Exhaust gas temperature is also noted. The procedure is repeated for the diesel fuel also.
Table 1: Properties of ethanol and diesel

\begin{tabular}{lcc}
\hline Properties & Ethanol & Diesel \\
\hline Latent heat $\left(\mathrm{kJ} \mathrm{kg}^{-1}\right)$ & 855.00 & 620 \\
Octane number & 106.00 & - \\
Lower calorific value $\left(\mathrm{KJ} \mathrm{Kg}^{-1}\right)$ & 26000.00 & 42500 \\
Boiling point $\left({ }^{\circ} \mathrm{C}\right)$ & 78.00 & $190-280$ \\
Self ignition temperature $\left({ }^{\circ} \mathrm{C}\right)$ & 420.00 & 325 \\
Specific gravity & 0.79 & 0.82 \\
Stoichiometric air-fuel ratio & 8.96 & 14.7 \\
\hline & & \\
Table 2: Specification of engine & & \\
\hline Manufacturer & Kirloskar \\
\hline Engine type & 4 stroke, single cylinder, \\
& water cooled, CI engine \\
Stroke & $110 \mathrm{~mm}$ \\
Bore & $95 \mathrm{~mm}$ \\
Power & $5.9 \mathrm{~kW}$ \\
Compression ratio & $16.5: 1$ \\
Rated speed & 1500 rpm \\
Loading type & Eddy current dynamometer \\
\hline
\end{tabular}

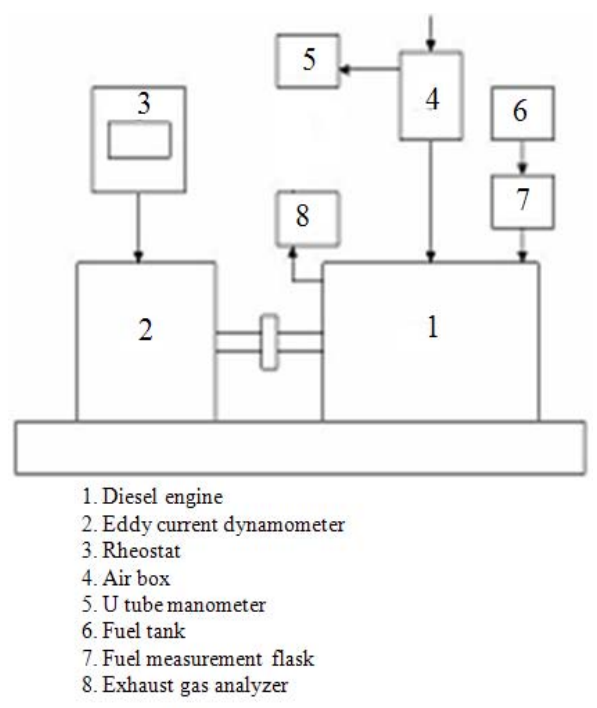

Fig. 1: Experimental setup

The experiment is repeated for various loads and respective readings are taken. After taking the above reading the engine parts were dismantled. The coated cylinder head, piston head and walls were assembled. The same procedure was repeated to predict the performance of the engine with zirconia coating.

\section{RESULTS AND DISCUSSION}

Brake thermal efficiency: Zirconia is a low thermal conductivity material. It will act as barrier for the heat transfer to the surroundings from the engine's combustion chamber and reduces the heat loss from the engine. Also as per first law of thermodynamics, the heat reduction in heat loss will ultimately increase the 
power output and thermal efficiency of the engine. Out of the four curves shown in the graph, two curves for diesel and two curves for ethanol are as an engine fuel.

From the Fig. 2, it is clear that the brake thermal efficiency of the engine for both diesel and ethanol are slightly increased after coating. For ethanol, the brake thermal efficiency is increased by $1.64 \%$. For diesel, the brake thermal efficiency is increased by $3.26 \%$.

Total Fuel Consumption (TFC): From the Fig. 3, it is clear that the total fuel consumption of the engine after coating is reduced. This will increase the brake thermal efficiency of the engine. This is due to the reduction of the heat loss to surroundings from the engine. From that, it is obvious that there will be an excess heat in the engine when compared with the amount of heat in the engine without coating, thereby increasing the brake thermal efficiency of the engine. Also it is suggested that the TFC is reduced up to some extent and it is increased for higher power requirement. For the ethanol, it is low up to $4 \mathrm{~kW}$. After that, it starts increasing. But in the case of diesel, this problem will not happen

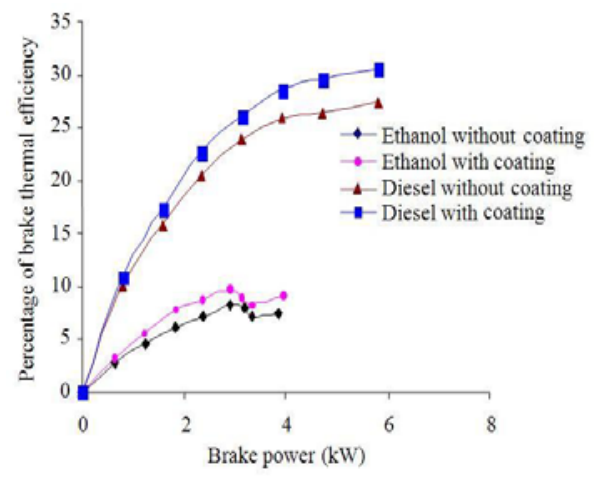

Fig. 2: Variation of Brake thermal efficiency with brake power

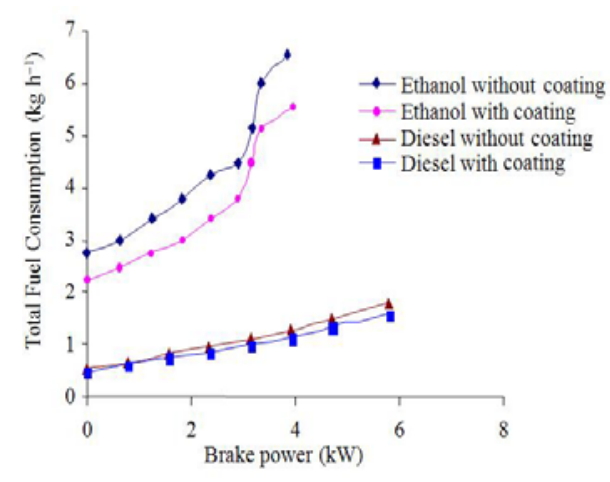

Fig. 3: Variation of Total fuel consumption with brake power
Specific Fuel Consumption (SFC): From the Fig. 4a and $b$, it is clear that SFC is decreasing after the coating due to the reasons that are discussed in the previous headings. There is slight variation in the curve for ethanol's SFC before and after coating. The reduction in SFC is $0.304 \mathrm{~kg} \mathrm{~kW} \mathrm{~h}^{-1}$ after coating for ethanol. But in the case of diesel, there is a very small variation in the reduction of SFC (i.e.,) $0.033 \mathrm{~kg} \mathrm{~kW} \mathrm{~h}^{-1}$.

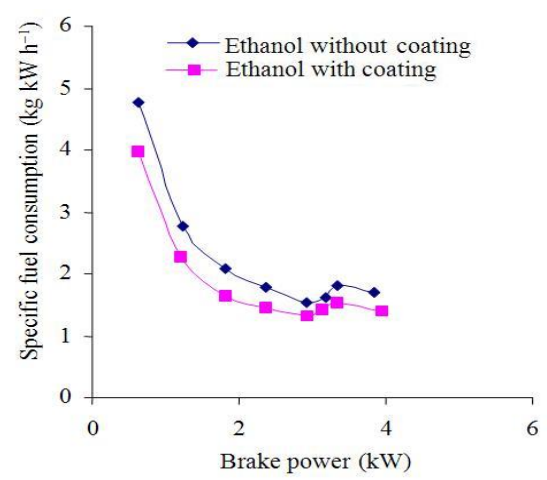

(a)

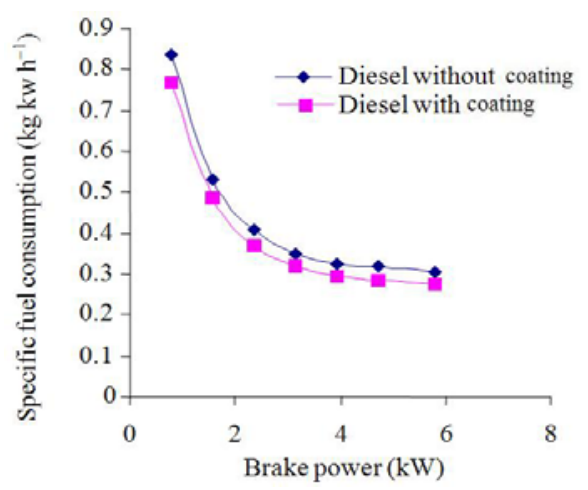

(b)

Fig. 4: (a) Variation of SFC (using ethanol) with brake power (b) Variation of SFC (using diesel) with brake power

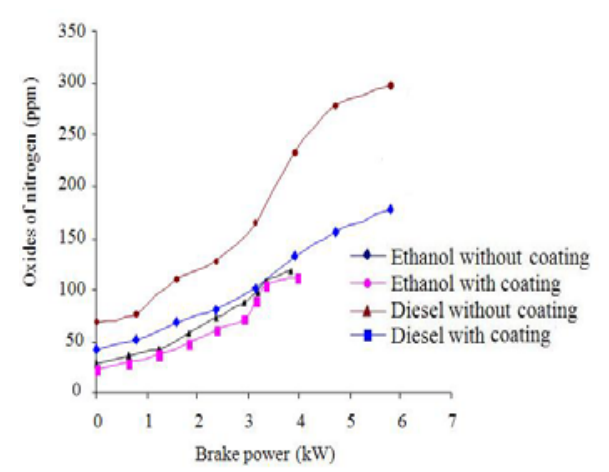

Fig. 5: Variation of NOx Emissions with brake power 
NOx emissions: From the Fig. 5, it is clear that there is a greater reduction of Oxides of Nitrogen due to coating because of nitrogen has absorbed by zirconia. Even though availability of oxygen high but availability of nitrogen is very less by the presence of impurities. Generally oxygen availability in diesel is high so at high temperatures nitrogen easily combines with oxygen but availability of nitrogen is very less due to coating and forms less NOx. It is observed that at part load (up to $2 \mathrm{KW}$ ) the NOx emissions are slightly increased for the engine with and without coating but there is considerable reduction in NOx after coating compared to without coating.

There is rapid increases of NOx above $2 \mathrm{KW}$ load and greater reduction of NOx with coating. For ethanol it is clear that there is a slight reduction of oxides of Nitrogen due to coating. It is observed that at part load (up to $2 \mathrm{KW}$ ) the NOx emissions are almost same for the engine with and without coating. And there is slight increases of NOx above $2 \mathrm{KW}$ load for both cases and considerable reduction of NOx with coating.

Unburned hydrocarbon emissions: From the Fig. 6, it is clear that, the unburned hydrocarbon emissions are reduced when the engine runs with coating. The unburned HC emissions are slightly higher for both the fuels when the engine runs without the zirconia coating. The main reason for this reduction in the unburned HC emissions is that at high temperatures the engine will have sufficient amount of oxygen which mixes with the HC emissions. As a result of this, the $\mathrm{HC}$ will split into $\mathrm{H}$ and $\mathrm{C}$ which mixes with $\mathrm{O}_{2}$, thereby reducing the $\mathrm{HC}$ emissions.

CO emissions: From the Fig. 7a and b it is clear that $\mathrm{CO}$ is decreased after the coating due to the complete combustion. The carbon monoxide, which arises mainly due to incomplete combustion, is a measure of combustion in efficiency .Generally oxygen availability in diesel is high so at high temperatures carbon easily combines with oxygen and reduces the $\mathrm{CO}$ emission. It is observed that at part load (up to $3 \mathrm{KW}$ ) the CO emissions are same for the engine with and without coating. And there is a slight increase of $\mathrm{CO}$ at full load condition when it runs without coating conditions. But in the case of engine with the ceramic coating, the CO emission is reduced. For ethanol also the same process as that of diesel occurs.

Exhaust gas temperature: From the Fig. 8 it is inferred that the exhaust gas temperature is higher for the engine runs under zirconia coated conditions than the engine runs under normal conditions. This is due to the more amount of heat generated inside the engine casing in which all amount of heat cannot be converted into useful work. EGT increase under this condition because of its heat is mixed with the exhaust gas.

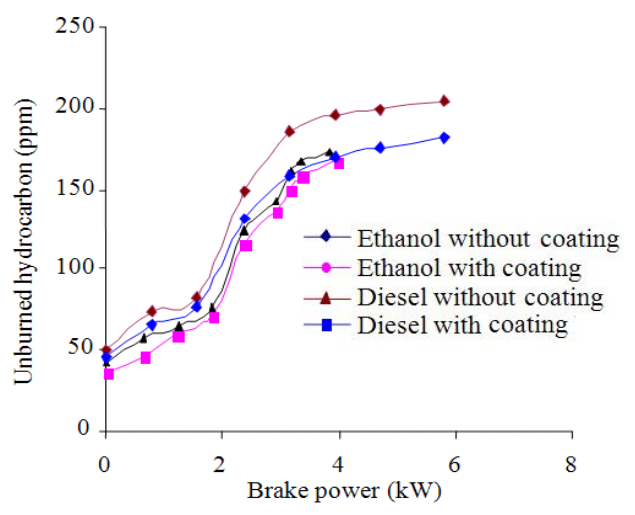

Fig. 6: Variation of unburned HC emissions with brake power

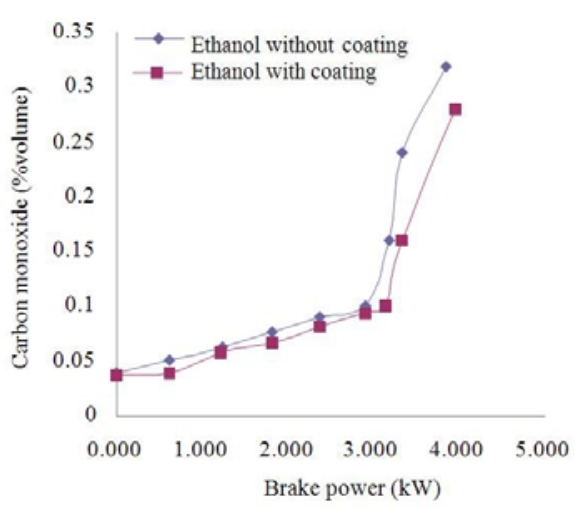

(a)

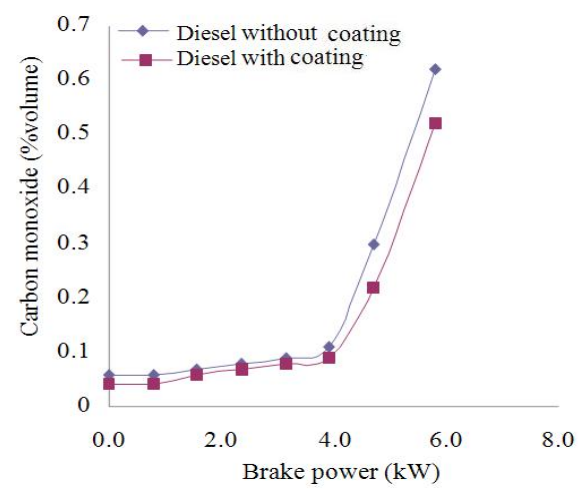

(b)

Fig. 7: (a) Variation of CO (using ethanol) with brake power, (b) Variation of CO (using diesel) with brake power 
Am. J. Applied Sci., 8 (4): 348-354, 2011

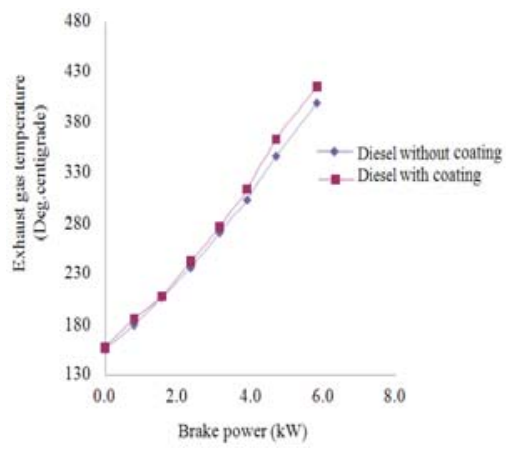

Fig. 8: Variation of exhaust temperature with brake power

\section{CONCLUSION}

Thermal efficiency is the true indication of the efficiency with which the chemical energy input in the form of fuel is converted into useful work. Improvement in engine thermal efficiency by reduction of in-cylinder heat transfer is the key objective of LHR engine research. As a low thermal conductivity material, zirconia is capable of reducing the heat loss from the cylinder to the surrounding this increases the life of the piston and piston rings. Due to the reduction in the heat loss to the surrounding, the power output and brake thermal efficiency of the engine is increased.

The specific fuel consumption is lower during all operating range of the base engine in the case of the use of LHR. Similarly, the specific fuel consumption increases during all operating range of the base engine in the case of the use of ethanol in LHR.

NOx emissions are mainly a function of a gas temperature and residence time. Most of the earlier investigations show that NOx emission from LHR engines is generally higher. This is due to higher combustion temperature and longer combustion duration. But in the present investigation there was a greater reduction of Oxides of Nitrogen due to coating because of nitrogen has absorbed by zirconia.

The emission of unburned hydrocarbon and $\mathrm{CO}$ also reduced because of the decreased quenching distance and increased lean flammability limit of LHR.

\section{REFERENCES}

Al Hasan, M., 2003. Effect of ethanol-unleaded gasoline blends on engine performance and exhaust Emission. Energy Conversion Manag., 44: 1547-1561. DOI: 10.1016/S0196-8904(02)00166-8
Al-Hasan, M., 2007. Evaluation of fuel consumption and exhaust emissions during engine warm-up. Am. J. Applied Sci., 4: 106-111. DOI: 10.3844/ajassp.2007.106.111

Beele, W., Marijnissen, G., A.V. Lieshout, 1999. The evolution of thermal barrier coatings-status and upcoming solutions for today's key issues. Surface Coatings Tech., 120: 61-67. DOI: 10.1016/S02578972(99)00342-4

Bekal, S. and T.P.A. Babu, 2008. Bio-fuel variants for use in CI engine at design and off-design regimes: An experimental analysis. Fuel, 87: 3550-3561. DOI: 10.1016/j.fuel.2008.07.001

Ciniviz, M., 2010. Performance and energy balance of a low heat rejection diesel engine operated with diesel fuel and ethanol blend. Transactions of the Canadian Society for Mechanical Engineering, 34: 93-104.

Garcia, E., P. Miranzo, R. Soltani and T.W. Coyle, 2008. Microstructure and thermal behavior of thermal barrier coatings. J. Thermal Spray Tech., 17: 478-485. DOI: 10.1007/s11666-008-9200-6

Hansen, A.C., Q. Zhang and P.W. Lyne, 2005. Ethanoldiesel fuel blends -- a review. Bioresour. Technol., 96: 277-285. PMID: 15474927

Jaichandar, S and P. Tamilporai, 2003. Low Heat Rejection Engines-An Overview. 1st Edn., SAE International, USA., pp: 17.

Kaleemuddin, S. and G.A.P. Rao, 2009. Development of dual fuel single cylinder natural gas engine an analysis and experimental investigation for performance and emission. Am. J. Applied Sci., 6: 929-936. DOI: 10.3844/ajassp.2009.929.936

Kamo, L., P. Saad, D. Saad, W. Bryzik and M.H. Mekari, 2006. Diesel engine cylinder bore coating for extreme operating conditions. 1st Edn., SAE Internationl, USA., ISBN-10: 0768016363, pp: 9.

Modi. A.J. and D.C. Gosai, 2010. Experimental study on thermal barrier coated diesel engine performance with blends of diesel and palm biodiesel. Fuels Lubricants, 3: 246-259.

Srinivasan, C.A. and C.G. Saravanan, 2010. Emission reduction in SI engine using ethanol-gasoline blends on thermal barrier coated pistons. Int. J. Energy Environ., 1: 715-726. 